\title{
EL IBERISMO EN ALICANTE DURANTE EL SEXENIO REVOLUCIONARIO
}

\author{
José Antonio Rocamora Rocamora
}

La aspiración a construir un Estado ibérico tuvo seguidores en España y en Portugal. Como otros nacionalismos unificadores -el germano, el italiano o el escandinavo- conoció una notable expansión a mediados del siglo XIX. Estos movimientos divergían sobre aspectos tan básicos como el régimen político o la configuración territorial de la nación. En España, el enlace dinástico, el destronamiento de los Borbones y la república federal fueron soluciones contempladas para lograr la unión.

Los últimos años del reinado de Isabel II vieron incrementarse los proyectos que asociaban su destronamiento con la unión ibérica, siendo consciente de ello la propia reina. En 1865, la prensa comentaba rumores de un levantamiento en Valencia al grito de «Unión Ibérica» para coronar al rey portugués ${ }^{1}$.

En agosto de 1868 El Comercio de Alicante divulgaba los frecuentes contactos diplomáticos entre Portugal e Italia y comentaba la llegada desde Lisboa a Madrid del consejero de Estado, que próximamente retornaría a Lisboa, mientras el representante de Lisboa en Madrid, que estuvo ocho días viajando de Madrid a la Granja, de la Granja a Lisboa, de Lisboa a Madrid y de la corte a San Ildefonso, regresó por último a su casa en Madrid². Tales noticias deben relacionarse con el deseo de parte de los conspiradores de entronizar a los Braganças. La implicación italiana se debía a que el rey portugués estaba casado con una italiana.

Las ideas iberistas circularon en diversos ámbitos, entre ellos un ámbito de socialización tan importante para la burguesía como los cafés. En 1863

1. Piqueras, José Antonio y Sebastià, Enric Sebastià, Agiotistas, negreros y partisanos, Valencia, 1991, pp. 135-140.

2. El Comercio de Alicante, 8 y 9-8-1868. 
existía un Café de la Iberia $a^{3}$ y en 1870 había en la ciudad cuatro cafés, entre ellos los denominados Los Dos Reinos y Nueva Iberia ${ }^{4}$. Éste debía ser sucesor del Café de la Iberia. La Iberia y Los Dos Reinos fueron denominaciones de dos periódicos que evidenciaban la aspiración iberista del progresismo. Si La Iberia es suficientemente explícito, Los Dos Reinos hacía referencia a los dos reinos ibéricos. Sus respectivos fundadores -Calvo Asensio y Peris y Valero- defendieron la unidad ibérica en la revolución de 1854. Fallecido Calvo Asensio, el líder progresista valenciano seguía defendiéndola en vísperas de la revolución de 1868.

El iberismo pudo dejar huellas en el epistolario o manifestarse en discursos, como sucedió en uno de Castelar en Elda ${ }^{5}$. Decisiones iberizantes tomadas en otros niveles repercutieron en Alicante. Fernández de los Ríos, ministro plenipotenciario en Lisboa, sugirió al ministro de Fomento la conveniencia de incrementar el comercio con Portugal. La maquinaria estatal entró en funcionamiento, encomendándose a la Junta Provincial de Agricultura, Industria y Comercio que solicitara a los industriales de la provincia que enviaran información sobre sus productos a cónsules y vicecónsules de Portuga ${ }^{6}$. Siendo nuestro propósito calibrar cuál era el estado de la opinión pública sobre la unión ibérica, consideramos suficiente para ello el análisis de la prensa, por contar con una cifra suficientemente elevada y políticamente diversificada de periódicos.

\section{La interinidad}

Dos figuras en Portugal atraían la atención de iberistas monárquicos: Fernando de Coburgo, viudo de Maria II, y su hijo el rey Luís I.

En un reciente estudio, Antonio Checa comenta la ausencia de una prensa numerosa que defendiese la candidatura portuguesa, atribuyéndolo a la carencia de apoyo de una potencia internacional o de sectores económicos relevantes ${ }^{7}$. A ello se sumaron otros factores, comenzando por la inexistencia de auténticos candidatos. Fernando de Coburgo no mostró interés por

3. GUTIÉRREZ LlORET, Rosa Ana, La República y el orden: burguesía y republicanismo en Alicante (1868-1893), Tesis doctoral (microficha), Alicante, 1987, p. 250.

4. Mira ABAD, Alicia, Secularización y mentalidades. El Sexenio Democrático en Alicante (1868-1875), Alicante, 2006, p. 312.

5. Monlleó Peris, Rosa, «La Gloriosa» en Valencia (1864-1869), Valencia, 1996, p. 268. Precisamente esta alusión nos es conocida por haber sido recogida en la prensa.

6. Archivo Histórico de la Diputación Provincial de Alicante, legajo GE-12.323/1.

7. CHeCA Godoy, Antonio, El ejercicio de la libertad. La prensa española en el Sexenio Revolucionario (1868-1874), Madrid, 2006, p. 76. 
convertirse en rey. Tampoco Luís I apostó con firmeza por una entronización que podía poner en peligro la corona portuguesa. Sus partidarios progresistas carecieron de algo tan básico como la connivencia-ya que no el liderazgo- de los candidatos. Los progresistas prefirieron actuar con discreción en lugar de popularizar la candidatura, seguramente por la falta de un candidato unánimemente aceptado por el gobierno y por la convicción de que la opinión pública estaba ganada de antemano.

Los reyes portugueses eran valorados por su respeto al funcionamiento de la monarquía constitucional, pero sobre todo porque podían culminar un proyecto nacionalista difundido en todos los grupos políticos: la unión ibérica ${ }^{8}$. Fernando de Coburgo parecía reunir condiciones idóneas. Por su edad, podría ser un monarca de transición, que consolidaría la monarquía constitucional, mientras en Portugal se disipaban las reticencias a la unión. Cuando muriese, Luís I reinaría en Iberia.

Los partidarios de Fernando de Coburgo pensaban que muchos republicanos -por su iberismo- darían prioridad a la patria sobre el régimen.

$\mathrm{Al}$ inicio del Sexenio, la propaganda iberista federal precedió a la monárquica. El 1 de noviembre El Comercio de Alicante -aunque progresista- publicaba una carta de Victor Hugo, esperando un renacimiento de España, que la pondría a la altura de Francia y el Reino Unido, mediante una república que permitiría

la unión de Portugal a España en un momento dado, por la mera atracción de la luz y de la prosperidad, porque la libertad es la piedra imán de las anexiones $^{9}$

Antes de alcanzar otros objetivos del republicanismo como la federación mundial o la europea, habría que conseguir la federación ibérica. Una larga carta de Castelar publicada en La Revolución contenía referencias a ella. Acusaba a la monarquía de no completar

la unidad nacional, porque en este mismo día tenemos separados del patrio suelo, a Portugal, que las brutalidades de nuestros monarcas nos arrancaron; y a Gibraltar que nos arrancaron sus discordias y sus sangrientas herencias.

Opinaba que los españoles repudiaban la entronización de extranjeros, pero no siendo los reyes portugueses percibidos claramente como tales, añadió:

Hubo un día que se les creyó capaces de imitar el ejemplo de Víctor Manuel, capaces de convertir el Portugal en el Piamonte de la Península Ibérica. Una

8. Sobre la unión ibérica, véase Rocamora Rocamora, José Antonio, El nacionalismo ibérico (1792-1936), prólogo de Celso Almuiña, Valladolid, 1994.

9. El Comercio de Alicante, 1-11-1868. 
larga serie de desengaños ha venido a imposibilitar esa solución. Parece que han aguardado los reyes de Portugal a que los liberales se hallaran fuera de la península para estrechar sus relaciones con la corte de España. ${ }^{10}$

Castelar conocía muy bien las esperanzas despertadas por los Braganças. De hecho, fue por ello acusado de ser monárquico, pudiéndose entender estas líneas como una autojustificación ${ }^{11}$. Tras criticar el servilismo de los Braganças hacia Isabel II y la mala administración de Portugal, expuso que el tiempo de las anexiones monárquicas había pasado debido a

los tristes resultados de Italia y a las violencias de Prusia. Nada importa que tengamos mucha tierra, si en esa tierra no hay espacio para nuestro hogar, aire para recoger el eco de nuestro pensamiento. Importa poco la magnitud del calabozo si al cabo somos un país esclavo (...). Además la anexión es impopular, muy impopular en Portugal. Ya saben los portugueses que ganan muy poco perdiéndose en un grande imperio militar (...). Yo deseo la unidad de la patria, la reinstalación de todos sus estados en la antigua autonomía, la unión de portugueses y españoles bajo una misma forma de gobierno, pero sé que no podremos atraernos a Portugal sino por el ejemplo magnífico de una gran libertad interior, y no podremos unirnos con Portugal sino bajo el régimen amplio de una república federativa. ${ }^{12}$

Tras una visita a tierras alicantinas, el dirigente republicano José María Orense redactó una «Carta a los republicanos de Europa» descartando las diversas candidaturas. Expresó sus dudas sobre la voluntad de venir de don Fernando, añadiendo que la unión sólo se produciría en la República Federal ${ }^{13}$.

El Comercio de Alicante siguió atentamente las noticias publicadas en la prensa extranjera. La francesa centraba sus especulaciones en Fernando de Coburgo, destacando que había un acuerdo franco-británico para entronizarlo, a pesar de su renuencia.

La Presse, que se hace particularmente el editor de esta noticia, manifiesta que la Francia, para evitar un Hohenzollern o un Montpensier, se resigna a la perspectiva de la unión ibérica, que sería la consecuencia inevitable del advenimiento de don Fernando. La eventualidad sería triste sin duda para nosotros [los franceses], pero el gabinete de las Tullerías la preferiría a combinaciones que le parecen actualmente más amenazadoras. ${ }^{14}$

10. La Revolución, 12 y 13-11-1868.

11. Con ocasión de una visita de los reyes portugueses a Madrid, Castelar participó en una manifestación de bienvenida que expresó el rechazo a Isabel II y el deseo de entronizar a los Braganças, logrando la unión ibérica. Véase FERNÁNDEZ DE LOS Ríos, Ángel, Mi misión en Portugal, París, s.d., pp. 221-223.

12. La Revolución, 14-11-1868.

13. La Revolución, 21-11-1868.

14. El Comercio de Alicante, 12 y 22-11-1868. 
Informó de las manifestaciones en Portugal el 1 de diciembre -aniversario del levantamiento contra España- que expresaban la oposición a la unión. El 24 comentó que su colega La Nación opinaba que el candidato preferible era un Bragança, que reuniría a otras ventajas la de ser el menos extranjero de cuantos aspiran al trono español. El 30 de diciembre reprodujo noticias de la prensa parisina sobre una entrevista privada de Napoleón III con Olózaga, embajador extraordinario y ministro plenipotenciario. Consideraba inusual tanto el título para el representante de un gobierno provisional como la audiencia privada, juzgándola un síntoma de que Olózaga era bien valorado ${ }^{15}$.

El 6 de enero de 1869 La Revolución reprodujo íntegramente el artículo « ¡Viva España con honra!», del madrileño La Voz del Siglo, precedido por un artículo de réplica $-« \mathrm{D}$. Fernando de Portugal»- del republicano alicantino José Cervera. El artículo madrileño defendía la candidatura como vía hacia la unión ibérica, siendo N. S. las iniciales de su autor. Cervera conocía la identidad del autor: Nicolás Salmerón. Su artículo confirmaba las esperanzas del iberismo monárquico sobre el apoyo -o la no beligerancia- del iberismo republicano a una monarquía que garantizase libertades y unión ibérica. Para republicanos como Cervera era necesario cerrar esta fisura, pero sin oponerse a una idea sugestiva y compartida. Cervera reconoció en Salmerón

la sublimidad del pensamiento y la abnegación hasta el punto de sacrificar un bello ideal en aras del engrandecimiento de la madre patria

Admitía simpatizar con la candidatura fernandina:

sí, lo digo muy alto, halagüeña me ha sido y me es la candidatura portuguesa, primero por los inmensos beneficios que la unidad ibérica nos resultaría, y segundo, por conocer de cerca a D. Fernando, y con esto dicho se queda que conozco sus brillantes virtudes, su modestia estremada (sic) y por consiguiente su antipatía al lujo y la molicie, su acendrado amor al pueblo, y por fin su exagerado respeto a las leyes

Sin embargo, estimaba que la candidatura era imposible y perjudicial para la patria, alegando que existía una diversidad histórica que hacía que cada pueblo conservara

sus trajes, sus idiomas y sus costumbres particulares, sin que hoy por hoy, ningún catalán deje de tenerse a ofensa el que le llamen castellano y viceversa.

Este apego a la identidad era más firme en

15. El Comercio de Alicante, 4, 24 y 30-12-1868. Olózaga, antiguo iberista, era partidario de don Fernando y por su estrecha relación con Napoleón III podía lograr que aceptara una candidatura que reduciría la influencia francesa en la península. 
el pueblo portugués, que se tiene en mucho y cree valer más de lo que en realidad vale (...), [y] en su generalidad se opondría a una unión que podría ocasionar graves perjuicios, por creer que se haría con menoscabo de su independencia

Reconocía que la extensión de la cultura facilitaría la unión, pero en aquel momento, lo que prosperaba en Portugal era un nacionalismo antiespañol. Sólo en Oporto y -en menor grado- en Lisboa y Coimbra había penetrado el liberalismo, por lo que la unión conllevaría la preponderancia de políticos españoles, generando malestar en Portugal. La historia política de los países era divergente y además don Fernando, una vez en España, podría cambiar sus modestos hábitos y ceder ante presiones para restaurar el fasto cortesano. Cervera cerró el artículo -como era norma en los republicanos- defendiendo la federación ibérica ${ }^{16}$.

La actitud favorable a la candidatura fernandina de La Voz del Siglo fue recogida también por El Comercio de Alicante, que el 2 de febrero informó de las simpatías del británico Spectator por una candidatura que favorecía una solución territorial grandiosa. A mediados de febrero, el periódico publicó varias noticias relacionadas con la unión ibérica. Hablaban de rumores sobre acciones de militares favorables a ella en Portugal, de la celebración en Lisboa de una manifestación iberista, bajo el lema ;Viva el rey Luis, rey de Iberia! y de la llegada de una gran flota británica a Lisboa. El 14 de febrero reproducía un manifiesto de Castelar a los electores de Zaragoza defendiendo una república federal que -conciliando unidad y diversidad- atrajese a Portugal. El 17 comentaba que el Diário Português negaba la veracidad del rumor de una sublevación militar iberista en Portugal, asegurando que a la unión deseada por el entonces ministro y antiguo iberista Latino Coelho, se enfrentaría al ejército y al pueblo portugués. ${ }^{17}$

El 18 de febrero, el artículo «La candidatura al trono», señalaba la candidatura de don Fernando como la escogida por el gobierno, lo que -según el diario madrileño La Correspondencia- irritaba al Reino Unido, cuyo gobierno habría ordenado la salida de una escuadra hacia Lisboa. Otros periódicos negaban esta información, asegurando que lo único cierto era que Olózaga había dejado arreglada en París la candidatura de don Fernando, que vendría en el momento en que lo proclamasen las Cortes y se lo pidiese Napoleón III, estando el Reino Unido dispuesto a aceptarla si se garantizaba que las dos coronas no recaerían en un mismo rey.

16. La Revolución, 6-1-1869.

17. El Comercio de Alicante, 11-1 y 2, 13, 14 y 17-2-1869. 
Entre tantos rumores, pensaban en El Comercio de Alicante que la candidatura de don Fernando era la que tenía más posibilidades de éxito. Cuestionaban la veracidad de la oposición y del veto británico a la unión, ya que nada impediría la unión si los pueblos lo deseaban:

los españoles están en el caso de prescindir de influencias extrañas que tiendan a mezclarse en nuestras decisiones (...) es forzoso que todos, todos los que aspiran a ver consolidado el triunfo de la revolución, antes de llamarse republicanos o monárquicos, progresistas o unionistas se llamen españoles. Ante ese nombre, ante la idea de salvar la patria deben desaparecer todas las ambiciones de bandería y las divisiones de escuela. ${ }^{18}$

El 19 de febrero El Comercio de Alicante publicaba que el madrileño La Iberia mantenía sus simpatías por don Fernando. El periódico de Sagasta decía que los enemigos de la candidatura portuguesa eran sobre todo neocatólicos y montpensieristas que pretendían desacreditarla, asegurando que don Fernando estaba secretamente casado con una artista de teatro, lo cual no tiene fundamento $^{19}$. El 21 de febrero se reprodujo parte de un artículo de La Iberia que tras analizar las causas de la separación, concluía que la unión era indispensable para el mutuo engrandecimiento. El 24 podía leerse una noticia del Comércio do Porto sobre dos largas reuniones del consejo de ministros con Luís I y su padre. Su contenido no había trascendido, pero el periódico portuense decía que don Fernando aceptaría la corona si se le ofrecía. El 26 se publicaban diversas noticias sobre la candidatura. La Monarquía Constitucional, de Madrid, decía haber recibido un telegrama de Lisboa desmintiendo rumores sobre la negativa de don Fernando a aceptar la corona, reafirmando las esperanzas puestas en él y pidiendo a los liberales de ambos países decisión, concluyendo con vítores a la unión de Iberia. El Diário Popular de Lisboa, en cambio, hablaba de las actividades de la Asociación Primero de Diciembre y del ambiente opuesto a la candidatura. Éste era probablemente el que hacía comentar a France que la candidatura fernandina, poco antes la mejor situada, parecía ahora descartada. Sin embargo, otros periódicos parisinos aseguraban que don Fernando aceptaría una corona ofrecida por las Cortes $^{20}$.

18. El Comercio de Alicante, 18-2-1869. El mismo día, un telegrama fechado en Lisboa el 15, reiteraba que los rumores de un golpe de Estado iberista en Lisboa eran infundados y de París llegaban informaciones -a través de La Liberté- que aseguraban que don Fernando aceptaría la corona.

19. El Comercio de Alicante, 19-2-1869. Sin embargo Montpensier, residente en Lisboa, conocía la relación de Fernando de Coburgo con una bailarina. Deseando para sí la corona, procuró, efectivamente, obstaculizar la de don Fernando, pero sin combatir abiertamente su principal base: la unión ibérica.

20. El Comercio de Alicante, 21, 24 y 26-2-1869. 
El progresista Eco de Alicante comenzó el 28 de febrero de 1869 una campaña favorable a la candidatura fernandina con el artículo «La solución». Decía que en números anteriores había expresado simpatías por don Fernando, excluyendo las demás candidaturas por sus

antecedentes eminentemente liberales, las aspiraciones de la nación y la notable circunstancia de ser la única candidatura que ha sido acogida con verdadero aplauso por la gran mayoría del país. La elección de D. Fernando de Portugal representaría una idea política de gran trascendencia, una aspiración justa y legítima de los españoles: la preparación de un acontecimiento de verdadera importancia histórica: la unión de los dos pueblos que viven en la península.

Aparecían los habituales argumentos sobre semejanzas entre los pueblos y las ventajas de un reinado de transición que acabase con los temores de una parte del pueblo portugués, achacables al mal recuerdo dejado por el reinado de Felipe II. Según el diario, era tal la acogida popular de la candidatura que montpensieristas y republicanos cifraban sus esperanzas en la renuncia del candidato ${ }^{21}$.

El Comercio de Alicante informaba el 2 de marzo de una manifestación antiiberista organizada por la Asociación Primero de Diciembre y el 5 de los insultos a unos españoles en Lisboa, al creerles agentes que trabajaban por la unión ibérica ${ }^{22}$.

El 4 de marzo, ante una pregunta lanzada desde La Revolución sobre si la defensa de la candidatura por el Eco de Alicante era la posición del partido progresista de Alicante, se les contesto que era de los redactores ${ }^{23}$. El mismo día La Revolución reprodujo un fragmento de un artículo de El Pueblo que informaba de una reunión de diputados para hablar sobre la candidatura portuguesa, comentando que por más acuerdos que se tomen y por más unión que se pretenda, lo cierto, lo indudable es que el portugués no quiere ser nuestro amo. Poco después, en un artículo contra los montpensieristas, reprodujo fragmentos de El Amigo del Pueblo, comentando que en Lisboa se incrementaban los artículos contra la candidatura y contra la unión. Dichos artículos estaban inspirados y pagados, según se asegura públicamente, por el mismo duque de Montpensier ${ }^{24}$.

El Eco de Alicante publicó el 7 de marzo un artículo destacando las bondades de la unión ibérica. Criticaba a los republicanos, que no se enfrentaban a

21. Eco de Alicante, 28-2-1869.

22. El Comercio de Alicante, 2 y 5-3-1869.

23. Eco de Alicante, 4-3-1869

24. La Revolución, 4 y 6-3-1869. 
ella para evitar que su imagen quedara dañada, pero en lugar de trabajar por la difusión de la idea, la presentaban como irrealizable. Se reconocía la existencia en Portugal de opositores a la unión, pero también de un gran partido de iberistas, en donde figuran muchas de las primeras ilustraciones del vecino reino, partido que va aumentando de día en día y que acabará por ser dueño de la opinión cuando se demostrase que la unión lejos de arrebatarles su independencia, se la dará perfecta y completa, al pertenecer a un gran Estado y escapar de la tutela británica. Si en el presente la unión era imposible sin recurrir a la violencia, lo que procedía era preparar la unión para realizarla pacíficamente. Ironizaba sobre el argumento republicano de que el rechazo de los portugueses era a la unión monárquica y no a la federal, dejando a los lectores que opinasen si la conducta de este partido respecto a la cuestión ibérica es digna. Para los redactores la respuesta era clara: los republicanos habían olvidado el deber de procurar la ventura y la prosperidad de la patria ${ }^{25}$.

El 11 de marzo reproducía un artículo de La Iberia crítico con Montpensier, opinando que

el pueblo español aspira a otro príncipe que, con más garantías para nuestra libertad y nuestros derechos, trae consigo grandísimas probabilidades de realizar, en un plazo no muy lejano, la idea nacional y gloriosa que acarician hace tanto tiempo los más ilustres hombres de dos pueblos hermanos, que miran con sentimiento la débil barrera que nos separa, y hacen patrióticos esfuerzos para estrechar de nuevo los lazos de la unión ibérica, que tantos días de gloria han de proporcionar a portugueses y españoles ${ }^{26}$

Ante las críticas del Eco de Alicante, el 11 de marzo buena parte del contenido de La Revolución se dedicó a la cuestión ibérica. El artículo «Unión ibérica» situaba la idea entre las de mayor importancia política y social. Adoptaba una posición favorable, manifestando una disposición a trabajar por ella hasta su culminación, que requeriría que Portugal también desease la unión. Quienes defendían la candidatura de don Fernando sabían que en aquellos momentos no era así y que su coronación no implicaría la unión.

Otro artículo -del corresponsal en Madrid- comentaba que los diputados monárquicos -salvo los unionistas- ensalzaban en privado las ventajas de la unión y las virtudes de don Fernando. Pero, en público, todos enmudecen y tratan, por todos los medios, de evitar cualquier linaje de compromisos. Atribuía esta contradicción a la influencia de Prim, que no mostraba sus preferencias,

25. Eco de Alicante, 7-3-1869.

26. Eco de Alicante, 11-3-1869. El mismo día se publicó la Balada de Iberia, compuesta en enero por Ventura Ruiz Aguilera, presentando la unión ibérica como un enlace matrimonial, augurando un feliz futuro a Iberia. 
haciendo que muchos tampoco lo hicieran para evitar contrariarle ${ }^{27}$, cuando precisamente la candidatura y la unión ibérica tenían en Prim uno de sus principales valedores.

El 19 de marzo el Eco de Alicante aseguró que en la última reunión del Senado se había debatido sobre las candidaturas. La de Montpensier habría sido rechazada por unanimidad, lo que celebraba, porque no representaba una idea política de poca o mucha importancia para los intereses de la nación, repitiendo los argumentos sobre la conveniencia de la candidatura fernandina ${ }^{28}$.

El 24 de marzo El Comercio de Alicante reafirmó su adhesión a la candidatura, opinando que la apoyaban hombres sensatos que anteponían los intereses generales a los partidistas, dando como muestra de ello el tono con el que trató La Revolución su figura en un artículo del corresponsal en Madrid del día 23, interpretando injustificadamente lo que era un mero elogio de su persona como un apoyo a su candidatura ${ }^{29}$.

Según El Comercio de Alicante, el ministro de Estado afirmó el 31 de marzo que no existía una notificación oficial sobre una renuncia de don Fernando ${ }^{30}$. El mismo día, La Revolución reprodujo un artículo de O Diário Português para insistir en la imposibilidad de la unión monárquica. El periódico portugués alertaba ante las maniobras diplomáticas españolas sobre el riesgo que implicaría una república en España para facilitar la aceptación de don Fernando ${ }^{31}$. El 3 de abril se informaba de rumores sobre un telegrama de renuncia de don Fernando, acusando a los montpensieristas de propalarlos. Para La Iberia se trataba de una noticia falsa y negaba que el embajador de Portugal hubiese hablado sobre la cuestión con miembros del gobierno ${ }^{32}$.

El Comercio de Alicante publicaba el día 7 que diversos telegramas indicaban que la candidatura fernandina era la más sólida en el gobierno y entre los diputados, habiéndose decidido un viaje de Olózaga a Lisboa para negociar. El madrileño El Imparcial veía en don Fernando el símbolo de una gran idea que la generación futura se encargará de realizar. El 8 abril El Comercio de Alicante comentaba la propuesta de The Morning Herald para casar al hermano menor de Luís I con la hija del duque de Montpensier. El matrimonio subiría al trono cuando falleciera don Fernando, evitando que un rey ciñera simultáneamente

27. La Revolución, 11-3-1869. El 16 de marzo un artículo de Fernando Garrido reiteró el ideal federalista ibérico.

28. Eco de Alicante, 19-3-1869.

29. El Comercio de Alicante, 24-3-1869. Este artículo fue aplaudido por el Eco de Alicante el 25-3-1869.

30. El Comercio de Alicante, 2-4-1869.

31. La Revolución, 2-4-1869.

32. Eco de Alicante, 3-4-1869. 
ambas coronas ibéricas. De París llegaban noticias sobre un encuentro de Isabel II con el embajador portugués, que le comunicó que ningún Bragança aceptaría la corona española. El 9 de abril, la prensa que llegaba de Madrid no daba crédito al rechazo de la corona por don Fernando. Sin embargo, el periódico progresista comentaba que el día anterior, entre los asistentes a la romería a la Santa Faz, se había mostrado la pesadumbre por esta negativa. A pesar de ello, el artículo «Inquietudes» renovaba su confianza en el único candidato aceptable, apuntando -no obstante- que si la negativa fuese firme, se podría hallar otro candidato para establecer una monarquía constitucional ${ }^{33}$.

El 10 de abril La Revolución publicó un texto de Froilán Carvajal, reaccionando a la publicación del telegrama. Como el rechazo implicaba una previa -oferta que Sagasta desmintió en las Cortes- acusó al gobierno de pretender imponerse sobre la voluntad popular ${ }^{34}$.

El extracto de la sesión de las Cortes del día 7 de abril -publicado en El Comercio de Alicante- reproducía la crítica de Castelar al telegrama de don Fernando, un Coburgo, un principillo alemán ha dado una bofetada en la mejilla a la nación española (...). España tiene una corona demasiado grande para una cabeza tan chica. Una carta del corresponsal en Madrid de El Comercio de Alicante reconocía que el rechazo había desvanecido las ilusiones de los iberistas, ilusiones que a decir verdad, tenían un noble sentimiento de amor patrio ${ }^{35}$.

El 17 de abril Carvajal reiteraba que el pueblo rechazaba a cualquier candidato, incluyendo a los portugueses y el 20 de abril, el corresponsal en Madrid, volvía a hablar de la candidatura portuguesa. Según la prensa madrileña, don Fernando había escrito a Serrano, negando haber pretendido ofender a los españoles y mostrando sorpresa por lo ocurrido, ya que Prim, Olózaga y Sagasta tenían constancia desde hacía tiempo de su propósito de no aceptar la corona. El consejo de ministros del día 15 analizó la carta de don Fernando y se amonestó -siempre según el corresponsal- a quienes, conociendo la decisión del rey, se empeñaron en ofrecerle la corona. Días después el corresponsal madrileño refería una reunión de dirigentes monárquicos. Topete, Serrano y miembros de la Unión Liberal habrían declarado -ante un intento de excluir del trono a cualquier Borbón- que tenían compromisos con el duque de Montpensier y que si aceptaron la candidatura de don Fernando fue por el deseo retornar pronto a la estabilidad, volviendo -tras su fracaso- a poner sus esperanzas en Montpensier ${ }^{36}$.

33. El Comercio de Alicante, 7, 8 y 9-4-1869.

34. La Revolución, 10-4-1869.

35. El Comercio de Alicante, 11 y 15-4-1869.

36. La Revolución, 17, 20 y 23-4-1869. 
En la sesión de las Cortes de 24 de abril, el republicano García López criticó la política exterior gubernamental, por crear puestos diplomáticos inútiles, como el del ministro plenipotenciario en Lisboa, que no evitó el desaire de don Fernando, a pesar de que la cuestión no era un secreto en Portugal. Buscar la unión ibérica a través de él -añadía- fue una ilusión, pues el principio de las nacionalidades no lo materializaban los reyes, sino los pueblos y el portugués deseaba la federación ${ }^{37}$.

Pocos días después J. F. González arremetía contra los montpensieristas, que -conscientes de su impopularidad-intrigaron contra la candidatura portuguesa para, una vez eliminada, manifestar sus ambiciones. El mismo número reproducía un artículo de Delescluze publicado en el periódico parisino Le Reveil para avalar las tesis antimonárquicas y difundir el ideal republicano, opinando

que no es temerario afirmar que la Península Ibérica ha de ofrecer en breve a Europa el magnífico espectáculo de una nación regenerada. ${ }^{38}$

Un editorial de 19 de mayo del Eco de Alicante se resistía a dar por definitivamente cerrada la candidatura. Días después se reproducía la sesión de las Cortes del 10 de mayo. García Ruiz criticó a Olózaga porque condicionó su participación en la conspiración contra Isabel II a la entronización de don Fernando. Olózaga reconoció que siempre había pensado en un candidato que aproximara una unión que considero, como he dicho antes, muy útil para todos ${ }^{39}$.

El periódico progresista reprodujo fragmentos de la sesión de las Cortes de 20 de mayo. Castelar se opuso a cualquier candidatura, rechazando la vía diplomática de Olózaga para lograr la unión ibérica porque carecía de candidato y porque había alejado la unión bajo la república. En la sesión de 7 de junio, Castelar habló de la expansión del republicanismo en Portugal y en la del 8, ironizó sobre don Fernando, a quien Sagasta llamaba «su rey». Tras indicar los sobrenombres de los siete reyes con ese nombre, le llamó Fernando VIII, el Imposible. Castelar -ante la persistencia de dudas sobre su actitud hacia la candidatura antes de la revolución- negó haberla defendido, indicando que ésta fue promovida por una parte del progresismo, mientras otra fracción, en la que estaba Sagasta, no había estado tan convencida de la conveniencia del cambio dinástico.

Sagasta respondió a Castelar. Dijo que tras el fracaso del levantamiento de 1866, hubo una reunión de progresistas y demócratas en casa de Olózaga,

37. Eco de Alicante, 29-4-1869.

38. La Revolución, 25-4-1869.

39. Eco de Alicante, 19 y 23-5-1869. 
conviniéndose derribar a los Borbones. También hubo otra reunión en la redacción de La Iberia, asistiendo Martos, Castelar, Ruiz Zorrilla y él, manifestándose un consenso sobre los Braganças. Sagasta dijo no haber defendido entonces la entronización por no estar seguro de la voluntad de don Fernando ni de la del país y añadió que antes de la revolución no se creía posible la república y lo único que se deseaba era acabar con la dinastía y sustituirla por otra, preferiblemente la de Bragança, que pondría la primera piedra del gran edificio de la unión peninsular. Castelar reiteró sus ideales, ofreciéndose a traer ejemplares de un folleto suyo donde defendía la unidad de la patria, la unión de portugueses y españoles bajo la república federal ${ }^{40}$.

El 5 de junio La Revolución publicaba un artículo en la habitual línea federalista, rechazando a don Fernando por la oposición de la nación portuguesa y a la ofensa que éste había hecho a la nación española, que no aceptaría un rey extranjero ${ }^{41}$.

El Eco de Alicante reprodujo un fragmento de un artículo publicado en Alemania, según el cual, el resultado de una república federal sería la absorción de Cataluña, Aragón y Baleares por Francia, la de Galicia y otros territorios por Portugal y la de Andalucía por Marruecos, quedando el resto fragmentado en estados similares a Andorra ${ }^{42}$.

Al debatirse en las Cortes el proyecto de ley de Regencia, Navarro y Rodrigo dijo que debía comenzarse por una combinación muy patriótica: podía votarse un príncipe de la dinastía portuguesa que viniera a realizar la obra magnífica de la completa unidad de la Península, que no había conseguido el absolutismo de Felipe II. Por sus implicaciones patrióticas, había sido defendida por destacados diputados, explicando que su fracaso no se debía a lo que se había dicho -las antipatías de los portugueses, el desinterés del candidato, el miedo de Luís I a perder el trono portugués o las intrigas de otros candidatos- sino a la oposición francesa. El 14 de junio Castelar volvía a hablar del épico sueño de la unión de España y Portugal bajo el cetro de Fernando VIII. El 12 de agosto el Eco de Alicante, recogió comentarios del Boletín Diplomático sobre el encuentro de Olózaga con Nigra -embajador italiano- en París, cuyo objetivo sería tratar de la candidatura de Luís I. También se noticiaba la entrega de credenciales a éste por el ministro plenipotenciario Fernández de los Ríos, quien abogó por el estrechamiento de las relaciones entre los pueblos hermanos ${ }^{43}$.

40. Eco de Alicante, 25 y 26-5-1869, 11 y 12-6-1869.

41. La Revolución, 5-6-1869.

42. Eco de Alicante, 8-6-1869.

43. Eco de Alicante, 17 y 18-6 y 12-8-1869. Ferviente iberista, Fernández de los Ríos tenía como objetivo principal relanzar la candidatura portuguesa, pero no desaprovecharía 
El 30 de noviembre de 1869 un telegrama de Lisboa afirmaba que ganaba el terreno de un tratado comercial con España. Los montpensieristas, conociendo el intento de reabrir las negociaciones con don Fernando, combatieron cualquier posibilidad de acuerdo, como se reflejó el 10 de diciembre el Eco de Alicante. Días después se hablaba del malestar en el ejército y de la llamada a Lisboa de Saldanha, prestigioso militar y conocido iberista ${ }^{44}$.

\section{La monarquía de Amadeo I}

Tras la coronación de Amadeo I y hasta la proclamación de la república se constata una reducción de artículos iberistas y una modificación de su contenido. No existiendo para los monárquicos una vía clara para la unión a corto plazo, canalizaron su iberismo hacia la mejora del conocimiento del vecino ibérico.

Los republicanos, en cambio, podían mantener su defensa de la República Federal Ibérica. El 10 de abril de 1872 La Tertulia, periódico radical, reprodujo un anuncio del Diário de Avisos de Lisboa sobre la creación de una agencia para comerciar con España, lo que se consideraba útil al comercio y a la industria de nuestro país, cuyas relaciones con Portugal se estrechan más y más cada día $a^{45}$.

El artículo «Tipos lusitanos», publicado por La Tertulia tenía un carácter divulgativo, comentando los rasgos culturales más destacados de las regiones portuguesas ${ }^{46}$. El 20 de agosto de 1872 se publicaba un largo artículo, «Recuerdos de Portugal», de Modesto Fernández y González. Tras afirmar la identidad de costumbres, lengua, religión, derechos civiles y políticos o clima, comentaba la existencia de una recíproca indiferencia que los gobiernos habían procurado -especialmente en los últimos tiempos- eliminar. Elogió la labor cultural desarrollada en Lisboa por Fernández de los Ríos y lamentaba que pocos españoles leyesen libros portugueses, señalando excepciones entre las que se contaban notorios iberistas como Romero Ortiz, Joaquín Benigno

oportunidades para mejorar las relaciones económicas y culturales entre los dos países (Eco de Alicante, 6-4 y 18-5-1871).

44. Saldanha dijo en una carta que a pesar de su amistad con políticos tan dispares como Olózaga, Castelar, Serrano y Prim, todos ellos sabían que combatiría por la independencia portuguesa. En la práctica, intentó -en vano- facilitar la negociación con don Fernando. Eco de Alicante, 30-8 y 10, 11 y 12-12-1869.

45. La Tertulia, 10-4-1872. El mismo día reprodujo un artículo de Luís Teste-corresponsal en Madrid- publicado en el Journal de Paris sobre Castelar, a quien había entrevistado. Castelar propugnó la Federación Latina, ante el escepticismo de Teste.

46. La Tertulia, 25-4-1872. También tuvieron carácter divulgativo algunos artículos publicados por la Revista de Instrucción Pública (10 y 20-9 y 31-12-1871). 
Martínez, Castelar o el propio Fernández de los Ríos. Opinaba que no existía en aquel momento una voluntad de alcanzar la unión y que

Sólo conociéndose y apreciándose mutuamente, sin perder nada de su autonomía e independencia podrán llegar a ser hermanos ambos pueblos.

Una vía para conseguirlo era promover obras sociales en Portugal. Sin embargo, la mayor parte del artículo carecía de un contenido explícitamente iberista ${ }^{47}$.

Tras un atentado contra Amadeo I, La Tertulia reprodujo el artículo «Fraternidad peninsular», publicado por La Tertulia de Madrid recogió muestras de solidaridad en Portugal y el 25 de septiembre se comentó la aparición en Lisboa de la Revista Ibérica, que defendía la república federal con un evidente matiz socializante $e^{48}$.

\section{La República}

El cambio de régimen podría haber abierto las puertas a un proceso integrador ibérico. El iberismo de los principales líderes republicanos españoles era conocido. Sin embargo, las vicisitudes internas hicieron que sólo en los primeros momentos se prestara atención a la unión ibérica.

Apenas proclamada la república, el republicano El Municipio, que impulsaba Maisonnave, figura muy próxima a Castelar, publicó en primera página el artículo «Unión ibérica», firmado precisamente por E. C. (Emilio Castelar). Caída la corona de Amadeo, vaticinaba una breve vida a su dinastía en Italia y a la de su cuñado, el rey portugués. Castelar sabía que la proclamación de la república había repercutido en Portugal, destacando que en su ejército se retrata el más puro amor a la democracia, confiando en que pronto habría un movimiento republicano. Portugal, parte de la Península Ibérica, estaba separado de forma antinatural

¿Por qué han de vivir separados los hermanos? (...)

Portugal y España están destinados por la Providencia para constituir una sola nación, puesto que no están separados por ninguna de esas divisiones naturales como lo es la cordillera de los Pirineos que nos separan de Francia, el carácter portugués es el español mismo; su lengua es un compuesto de gallego y andaluz, provincias con las que confina el reino de Portugal; su historia es la nuestra; los grandes descubrimientos se han efectuado por estas dos naciones.

47. La Tertulia, 20-8-1872. Con ligeras modificaciones, este artículo fue publicado por El Constitucional el 15-11-1873.

48. La Tertulia, 3 y 25-9-1872. 
La unión debía producirse desde la libertad de ambas partes y no por la fuerza, como en tiempos de Felipe II. Confiaba que el movimiento progresivo del mundo, impulsor de la unión, haría que

dentro de un breve plazo, desde el cabo Ortegal al de Gata, y desde el de San Vicente al de Creus, habrá una sola nación que vivirá felizmente a la sombra de la República. ${ }^{49}$

Los días 11 y 12 de marzo de 1873 se publicó el artículo «Las repúblicas latinas», presentando la España republicana era un modelo para otros pueblos europeos, especialmente los latinos y entre ellos

Portugal, separado de nosotros por la tiranía de los reyes y que hoy dirige sus atribulados ojos a nuestra patria, como esperando de ella la salud que tanto necesita. (...). La mayor parte de la prensa portuguesa, tan amante de la independencia de su país, comprende que ya no es posible la dinastía de Braganza (...), la opinión pública aclama la República como la única solución posible (...).

Todo anuncia, pues, que pronto la democracia proyectará su benéfica sobra desde Cádiz a los Pirineos y desde el Mediterráneo al Atlántico, formando Portugal y España una sola nación, y unidas ambas por comunes aspiraciones, realizarán bajo la bandera de la República la tan deseada unión ibérica, sueño dorado de los grandes genios de ambos países. ${ }^{50}$

Pero el 18 de abril de 1873 el periódico sagastino El Constitucional reprodujo un artículo sobre el fracaso de Amadeo I, dando otra visión de Portugal: un país que tras ser una provincia española estaba ahora políticamente más avanzado y con una dinastía sólida ${ }^{51}$.

El Municipio insertó el 21 de mayo una carta de Félix Pyat, uno de los líderes de la Comuna, que hablaba de una posible guerra entre latinos y sajones, opinando que muy pronto, cien millones de latinos vivirían bajo regímenes republicanos. Al enumerar los territorios latinos, España y Portugal aparecían englobados en Iberia ${ }^{52}$.

El Constitucional recogió el 12 de agosto de 1873 opiniones de un periódico portugués sobre el oportunismo de muchos federalistas españoles, que ponían sus esperanzas en la unión geográfica cuando las naciones se construían por voluntades, costumbres, historia e intereses económicos ${ }^{53}$. El 3 de enero de 1874 reprodujo un artículo publicado en La Iberia criticando a Salmerón. Recordaba que un manifiesto a sus electores defendió a Fernando

49. El Municipio, 21-2-1873.

50. El Municipio, 11 y 12-3-1873.

51. El Constitucional, 18-4-1873.

52. El Municipio, 21-5-1873.

53. El Constitucional, 12-8-1873. 
de Coburgo, candidato reclamado por la patria ibérica y -como candidato nacional-superior a las divisiones políticas, capaz de preparar la formación de la nación más libre y poderosa de Europa Occidental ${ }^{54}$. En junio de 1874 informó sobre el viaje de Castelar a Portugal, donde habría reconocido que no tenía sentido que los portugueses alterasen la paz en que vivían ${ }^{55}$.

A fines del Sexenio, con el legado de la Gloriosa en crisis y un país desestabilizado, se replanteó -si bien con menor fuerza- la unión ibérica monárquica.

El 5 de septiembre de 1874 El Constitucional reprodujo un artículo del Diário Popular. El periódico portugués, en vista del incremento del gasto militar, se preguntaba si el portugués Fontes pensaba ser un nuevo Cavour o Bismarck. El diario temía que la tensión franco-germana afectase a la península, alineándose Alemania con España -molesta por la benevolencia francesa con el carlismo- que como recompensa obtendría Portugal. Para Alemania sería preferible, en caso de guerra con Francia, no tener aquende los Pirineos más que una nación, y suspirando casi todos los partidos españoles por la unión ibérica, aún bajo el centro de la dinastía portuguesa, es natural que en los planes de Mr. Bismark entre la idea de formar la Iberia por la anexión de Portugal a España, constituyendo una monarquía constitucional con el rey de la casa de Braganza, dejando a Francia sin aliados en la península. Italia debía también ser partidaria de esta solución por ser aliada de Alemania y por el parentesco con la dinastía de Braganza. Por el contrario a Francia le interesaba no sólo la separación ibérica, sino incluso el enfrentamiento. El diario opinaba que habría que armar e instruir a todo el pueblo para resistirse a una eventual invasión ${ }^{56}$.

Ante este rebrote iberista, El Constitucional publicó un artículo que plasmó lo que sería la actitud mayoritaria entre los monárquicos hacia la unión ibérica en las siguientes décadas: algo deseable, pero irrealizable a corto o medio plazo. El articulista opinaba que

La unión ibérica no es el ideal al que debemos aspirar al presente y del que podemos esperar nuestro engrandecimiento.

Como los portugueses eran reacios a la unión, había que posponerla hasta que -desvanecido todo temor- se pudiese alcanzar por vías pacíficas.

Hoy por hoy las nacionalidades española y portuguesa son distintas, carecen de esos lazos de relación, de esa paridad de miras y aspiraciones, de esa igualdad y condiciones que deben existir como preparativo y precedente favorable para que la unión entre dos pueblos sea duradera.

54. El Constitucional, 3-1-1874.

55. El Constitucional, 9 y 11-6-1874. El 30-7-1874 reprodujo otro discurso de Castelar limitando la utilidad de la federación a los casos en que sirviese para unir estados 56. El Constitucional, 5-9-1874. 
Había que limitarse a mantener unas relaciones fraternales, conservando independencia y autonomía. Ésta debería preservarse incluso en el caso de que se alcanzase la unión ${ }^{57}$.

El Constitucional se hizo eco -a través del español La Prensa- del malestar en Portugal por la reactivación del iberismo español. Reprodujo un artículo que hablaba sobre rumores en Lisboa acerca de una oferta imperativa de la corona española a Luís I por el embajador alemán. La Prensa opinaba que la historia reciente aconsejaba a Portugal no arriesgar su paz y prosperidad uniendo su destino a la convulsa España. Curiosamente, las últimas referencias a la unión ibérica del período aluden a un ámbito tradicionalmente ajeno a los planteamientos nacionalistas ibéricos: el carlismo. En noviembre de 1874 El Constitucional hablaba de una carta que revelaría disensiones entre Carlos y su hermano Alfonso, cuya mujer, hija de Miguel de Bragança, querría alentar a los absolutistas portugueses para alcanzar la corona ibérica ${ }^{58}$.

\section{Conclusiones}

Aunque Alicante contó con representación consular de Portugal ${ }^{59}$, no existía una intensa relación económica ni desplazamientos significativos de personas entre Alicante y Portugal. Los proyectos ferroviarios iberistas tendían a favorecer la relación entre los puertos portugueses y el interior peninsular, lo que podría afectar negativamente a otros puertos, como el de Alicante. No hemos hallado valoraciones sobre esta posible repercusión de la unión ibérica ${ }^{60}$. Por lo tanto, parece que las posiciones hacia ésta deben poco a consideraciones de ámbito local.

La cuestión ibérica tuvo una presencia irregular en la prensa alicantina del Sexenio. El inicio del período, con la candidatura de Fernando de Coburgo, constituye el momento culminante. Era un momento en que quienes redactaban y leían esa prensa podían creer en la inminencia de la unión. Posteriormente los artículos iberistas descenderían, con altibajos, para no recuperar ya semejante nivel.

Al plantearnos el arraigo de las ideas iberistas, nos inclinamos a pensar que, al comenzar el Sexenio, estaban bastante difundidas en los círculos

57. El Constitucional, 27-9-1874.

58. El Constitucional, 29-10 y 7-11-1874.

59. Boletin Oficial de la Provincia de Alicante, 21-1-1874.

60. En Santander sí hubo reticencias a la unión ibérica por motivos económicos. Véase RUEDA, Germán, «El iberismo del siglo XIX. Historia de la posibilidad de unión hispano-portuguesa», en TORRE Gómez, Hipólito de la y Vicente, António Pedro (dirs.), España-Portugal. Estudios de Historia Contemporánea, Madrid, 1998, p. 199. 
políticos alicantinos. La unión ibérica aparece, más que como un concepto a definir, como un concepto conocido y cuyas ventajas son generalmente aceptadas. Se discutía sobre la forma de realizar la unión, pero no sobre su conveniencia en sí. Alguien que se hubiese enfrentado a este consenso, podría haberse arriesgado a ser tildado de antipatriota.

Pero la profundidad de las ideas no parece haber estado en consonancia con su extensión. Sus seguidores no demostraron un empeño continuado y terminarían anteponiendo otros objetivos a la unión en las convulsas circunstancias del Sexenio. Fracasadas las aspiraciones ibéricas monárquicas y republicanas, comenzaría en el último cuarto del siglo XIX un período de atonía iberista, en el que la unión ibérica, aun siendo algo deseable, se vería desplazada a un incierto y lejano futuro. 